\title{
Fatty Acid Compositions of Six Wild Edible Mushroom Species
}

\author{
Pelin Günç Ergönül, ${ }^{1}$ Ilgaz Akata, ${ }^{2}$ Fatih Kalyoncu, ${ }^{3}$ and Bülent Ergönüll ${ }^{1}$ \\ ${ }^{1}$ Department of Food Engineering, Faculty of Engineering, Celal Bayar University, 45140 Manisa, Turkey \\ ${ }^{2}$ Department of Biology, Faculty of Science, Ankara University, Tandogan, 06100 Ankara, Turkey \\ ${ }^{3}$ Department of Biology, Faculty of Science and Letters, Celal Bayar University, 45140 Manisa, Turkey
}

Correspondence should be addressed to Fatih Kalyoncu; fatih.kalyoncu@cbu.edu.tr

Received 30 January 2013; Accepted 29 May 2013

Academic Editors: I. Palomo and F. Perez

\begin{abstract}
Copyright (C) 2013 Pelin Günç Ergönül et al. This is an open access article distributed under the Creative Commons Attribution License, which permits unrestricted use, distribution, and reproduction in any medium, provided the original work is properly cited.

The fatty acids of six wild edible mushroom species (Boletus reticulatus, Flammulina velutipes var. velutipes, Lactarius salmonicolor, Pleurotus ostreatus, Polyporus squamosus, and Russula anthracina) collected from different regions from Anatolia were determined. The fatty acids were identified and quantified by gas chromatography and studied using fruit bodies. Fatty acid composition varied among species. The dominant fatty acid in fruit bodies of all mushrooms was cis-linoleic acid $(18: 2)$. Percentage of cis-linoleic acid in species varied from $22.39 \%$ to $65.29 \%$. The other major fatty acids were, respectively, cis-oleic, palmitic, and stearic acids. Fatty acids analysis of the mushrooms showed that the unsaturated fatty acids were at higher concentrations than saturated fatty acids.
\end{abstract}

\section{Introduction}

More than 2000 species of mushrooms exist in nature; however less than 25 species are widely accepted as food and only a few have attained the level of an item of commerce. Wild mushrooms are becoming more and more important in our diet for their nutritional, organoleptic, and pharmacological characteristics [1]. Based on their high mineral content, low fat, and low calories, the nutritional values of mushrooms have already been reevaluated [2]. Additionally, mushrooms have been known to have an effect on preventing several diseases such as cancer, hypercholesterolemia, and hypertension [3].

Dietary fat, a major constituent of the normal diet and thus a tight feedback regulator, is necessary to ensure balanced lipid homeostasis. Generally, lipid content of mushroom species is low. It is reported that, in fresh mushrooms belonging to different species, the lipid proportion per $100 \mathrm{~g}$ is $1.75-15.5 \%$ in dried mushroom since fresh ones contain high amounts of water [4]. Although the edible wild mushrooms command higher prices than cultivated mushrooms, people prefer to consume them due to their flavour and texture [5].
Therefore, it is necessary to investigate the levels of chemical and biochemical compounds in wild edible mushrooms, because many wild edible mushroom species are known to store high levels of several unsaturated fatty acids [6].

Many researchers have studied the fatty acid composition of several mushrooms and elucidated their nutritional roles in the human diet [7]. Barros et al. [1] reported that the major fatty acids of Agaricus arvensis, Lactarius deliciosus, Leucopaxillus giganteus, Sarcodon imbricatus, and Tricholoma portentosum were linoleic acid and oleic acid. Cordyceps sinensis is known to contain 16 kinds of amino acids, and $27.4 \%$ of its total fatty acids are polyunsaturated fatty acid (PUFA) [8]. Although many wild mushrooms have been used for medicinal purposes because of their useful components and biological activities, consumer have not been able to eat these mushrooms because of their relative scarcity. To commercialize wild mushrooms, many studies have focused on the development of artificial cultivation methods using various materials and conditions [9].

In this study, fatty acid composition of six wild edible mushroom species collected from different regions of Anatolia were analyzed to evaluate their nutritional values. 
TABLE 1: Fungarium numbers and locality information of six wild edible mushroom species.

\begin{tabular}{lccc}
\hline Species & Fungarium number & Coordinates & Localities \\
\hline Boletus reticulatus & 1091 & $\mathrm{~N} 41^{\circ} 03^{\prime}-\mathrm{E} 33^{\circ} 41^{\prime}$ & Ilgaz Mountain \\
Flammulina velutipes & 2127 & $\mathrm{~N} 39^{\circ} 56^{\prime}-\mathrm{E} 32^{\circ} 49^{\prime}$ & $\mathrm{N}$ Ankara \\
Lactarius salmonicolor & 2413 & $\mathrm{~N} 40^{\circ} 36^{\prime}-\mathrm{E} 31^{\circ} 17^{\prime}$ & $\mathrm{B}$ \\
Pleurotus ostreatus & 3093 & $\mathrm{~N} 39^{\circ} 56^{\prime}-\mathrm{E} 32^{\circ} 49^{\prime}$ & $\mathrm{N} 39^{\circ} 56^{\prime}-\mathrm{E} 32^{\circ} 49^{\prime}$ \\
Polyporus squamosus & 3091 & $\mathrm{~N} 41^{\circ} 06^{\prime}-\mathrm{E} 33^{\circ} 44^{\prime}$ & Ankara \\
Russula anthracina & 1184 & & Ankara \\
\hline
\end{tabular}

TABLE 2: Composition of fatty acids in six wild mushrooms (dry basis, \% of total fatty acid).

\begin{tabular}{|c|c|c|c|c|c|c|}
\hline & PS & $\mathrm{PO}$ & LS & $\mathrm{FV}$ & RA & $\mathrm{BR}$ \\
\hline C4:0 butyric acid & 0.03 & 0.06 & 0.09 & 0.05 & 0.01 & 0.06 \\
\hline C6:0 caproic acid & 0.03 & 0.07 & 0.03 & 0.02 & 0.01 & 0.17 \\
\hline C8:0 caprilic acid & 0.05 & 0.21 & 1.66 & 0.19 & 0.03 & 0.18 \\
\hline C10:0 capric acid & 0.74 & 1.36 & 0.16 & 0.06 & 0.08 & 0.20 \\
\hline C11:0 undecanoic acid & 0.09 & 0.07 & 0.03 & 0.04 & 0.10 & 0.87 \\
\hline C12:0 lauric acid & 0.10 & 0.21 & 0.17 & 0.26 & 0.04 & 0.06 \\
\hline C13:0 tridecanoic acid & 0.04 & 0.06 & 0.01 & 0.03 & 0.02 & 0.02 \\
\hline C14:0 myristic acid & 0.58 & 0.66 & 0.16 & 0.50 & 0.15 & 0.37 \\
\hline C14:1 myristoleic acid & 0.06 & 0.03 & 0.03 & 0.04 & 0.01 & 0.11 \\
\hline C15:0 pentadecanoic acid & 0.89 & 1.99 & 0.35 & 0.76 & 0.35 & 0.37 \\
\hline C15:1 pentadesenoic acid & 0.07 & 0.10 & 0.04 & 0.99 & 0.03 & ND \\
\hline C16:0 palmitic acid & 17.21 & 12.40 & 7.76 & 14.56 & 9.16 & 11.26 \\
\hline C16:1 palmitoleic acid & 0.65 & 0.46 & 0.22 & 0.70 & 0.64 & 0.75 \\
\hline C17:0 margaric acid & 0.48 & 0.21 & 0.22 & 0.07 & 0.08 & 0.28 \\
\hline C17:1 heptadesenoic acid & 0.16 & 0.04 & 0.03 & 0.06 & 0.08 & 0.99 \\
\hline $\mathrm{C} 18: 0$ stearic acid & 3.28 & 3.71 & 7.27 & 3.56 & 12.96 & 5.84 \\
\hline C18:1 trans-oleic acid & 0.07 & 0.05 & 0.05 & 0.06 & 0.04 & 0.12 \\
\hline C18:1 cis-oleic acid & 33.02 & 10.36 & 18.98 & 16.37 & 52.11 & 37.61 \\
\hline C18:2 trans-linoleic acid & 0.09 & 0.06 & 0.03 & 0.05 & 0.03 & 0.02 \\
\hline C18:2 cis-linoleic acid & 38.91 & 65.29 & 59.44 & 40.87 & 22.39 & 36.60 \\
\hline C18:3 linolenic acid & 0.27 & 0.03 & ND & 0.01 & 0.01 & ND \\
\hline $\mathrm{C} 18: 3$ gamma & 0.26 & 0.26 & 1.40 & 17.25 & 0.03 & 0.31 \\
\hline C20:0 arachidic acid & 0.30 & 0.13 & 0.45 & 0.19 & 0.21 & 0.58 \\
\hline C20:1 eicosenoic acid & 0.11 & 0.11 & 0.03 & 0.08 & 0.18 & 0.50 \\
\hline C20:2 eicosadienoic acid & 0.17 & 0.18 & 0.08 & 0.15 & 0.05 & 0.34 \\
\hline C21:0 heneicosanoic acid & 0.06 & 0.06 & 0.06 & 0.04 & 0.05 & 0.30 \\
\hline C20:3 $n=3$ cis-11,14,17-eicosatrienoic acid & ND & 0.01 & 0.03 & ND & ND & 0.04 \\
\hline C20:4 arachidonic acid & 0.04 & 0.02 & ND & 0.02 & ND & 0.11 \\
\hline C20:3 $n=6$ cis-8,11,14-eicosatrienoic acid & 0.10 & 0.02 & 0.05 & 0.06 & 0.02 & ND \\
\hline C22:0 behenic acid & 0.43 & 0.11 & 0.14 & 0.04 & 0.04 & 0.08 \\
\hline C20:5 eicosapentaenoic acid & 0.25 & ND & 0.24 & 0.47 & 0.24 & 0.45 \\
\hline C22:1 erucic acid & 0.16 & 0.24 & 0.20 & 0.12 & 0.23 & 0.27 \\
\hline C22:2 docosadienoic acid & 0.16 & 0.15 & 0.13 & 0.36 & 0.06 & 0.23 \\
\hline C23:0 tricosanoic acid & 0.42 & 0.02 & 0.03 & 0.03 & 0.02 & 0.03 \\
\hline C24:0 lignoseric acid & 0.52 & 0.48 & 0.42 & 0.30 & 0.43 & 0.51 \\
\hline C24:1 nervonic acid & ND & ND & ND & 0.16 & ND & ND \\
\hline C22:6 docosahexaenoic acid & 0.41 & 0.48 & 0.19 & 1.43 & 0.13 & 0.32 \\
\hline SFA (saturated fatty acids) & 25.19 & 21.77 & 18.96 & 20.67 & 23.72 & 21.14 \\
\hline MUFA (monounsaturated fatty acids) & 34.27 & 11.37 & 19.56 & 18.58 & 53.30 & 40.34 \\
\hline PUFA (polyunsaturated fatty acids) & 40.64 & 66.48 & 61.57 & 60.65 & 22.94 & 38.40 \\
\hline
\end{tabular}

PS: Polyporus squamosus; PO: Pleurotus ostreatus; LS: Lactarius salmonicolor; FV: Flammulina velutipes; RA: Russula anthracina; BR: Boletus reticulatus; ND: not determined. 


\section{Materials and Methods}

2.1. Samples. In this study, six wild edible mushroom species (Boletus reticulatus Schaeff., Flammulina velutipes (Curtis) Singer var. velutipes, Lactarius salmonicolor R. Heim \& Leclair, Pleurotus ostreatus (Jacq.) P. Kumm., Polyporus squamosus (Huds.) Fr., and Russula anthracina Romagn.) were analyzed for their fatty acid compositions. Origin and habitat information of these macrofungi has been given in Table 1 . All of the analyzed mushrooms were identified as edible macrofungi belonging to class Basidiomycetes. The samples of the above six species were collected from different regions of Anatolia. All macrofungi samples were deposited in the Biology Department, Celal Bayar University, Turkey.

2.2. Fatty Acid Composition. The dried mushroom samples were powdered to $\sim 1 \mathrm{~mm}$ particle size and used for analysis. Fatty acids were determined by gas-liquid chromatography with flame ionization detection (GLC-FID)/capillary column based on the ISO 5509 [10] trans-esterification method. The fatty acid profile was analyzed with a Chrompack CP 9001 chromatograph equipped with a split-splitless injector, a FID and a Chrompack CP-9050 autosampler. The temperatures of the injector and detector were $250^{\circ} \mathrm{C}$. Separation was achieved on a $50 \mathrm{~m} \times 0.25 \mathrm{~mm}$ i.d. fused silica capillary column coated with a $0.19 \mu \mathrm{m}$ film of CP-Sil 88 . Helium was used as carrier gas at an internal pressure of $120 \mathrm{kPa}$. The column temperature was $140^{\circ} \mathrm{C}$, for a $5 \mathrm{~min}$ hold, and then programmed to increase to $220^{\circ} \mathrm{C}$ at a rate of $4^{\circ} \mathrm{C} / \mathrm{min}$ and then held for $10 \mathrm{~min}$. The split ratio was $1: 50$, and the injected volume was $1.2 \mu \mathrm{L}$. The results are expressed in relative percentage of each fatty acid, calculated by internal normalization of the chromatographic peak area. Fatty acid identification was made by comparing the relative retention times of FAME peaks from samples with standards. A Supelco mixture of 37 FAMEs (standard 47885-U) was used. Some fatty acid isomers were identified with individual standards also purchased from Supelco [1].

2.3. Statistical Analysis. The data presented are the averages of the results of three replicates with a standard error of less than $5 \%$.

\section{Results and Discussion}

The fatty acid compositions of the wild edible mushrooms analyzed are shown in Table 2.

In the present work, fatty acid compositions of fruit bodies of six wild edible mushroom species (Boletus reticulatus, Flammulina velutipes var. velutipes, Lactarius salmonicolor, Pleurotus ostreatus, Polyporus squamosus, and Russula anthracina) were investigated. The fatty acid compositions were different among all species. Unsaturated fatty acid levels were higher than saturated ones. This agrees with the observations that unsaturated fatty acids predominate over saturated ones in mushrooms [11]. The carbon chain lengths of fatty acids were from 4 to 24. cis-Linoleic acid was the major fatty acid detected in all species. In addition to cis-linoleic acid, cis-oleic, palmitic, and stearic acids were the other abundant fatty acids in the mushrooms. These four fatty acids were present in all of the mushrooms examined. Similar observations have been made in other mushrooms $[1,2]$.

All the mushrooms analyzed contained large quantities of essential fatty acid, cis-linoleic acid. Essential fatty acids are fatty acids that humans and other animals must ingest because the body requires them for good health but cannot syntesize them [12]. cis-Linoleic acid (18:2) was obtained in high amounts in P. ostreatus (65.29\%). cis-Linoleic acid occurred in large amounts in the fruit bodies of L. salmonicolor (59.44\%) and F. velutipes (40.87\%) compared to other fatty acids. These results were in agreement with the previous reports that many mushroom species had high proportions of unsaturated fatty acids, especially linoleic acid $[13,14]$. It is known that linoleic acid is the precursor of 1-octen-3-ol, known as the alcohol of fungi, which is the principal aromatic compound in most fungi and might contribute to mushroom flavour [15]. The percentages of cis-oleic acid in the fruit bodies of $R$. anthracina, B. reticulatus, and P. squamosus were $52.11,37.61$, and $33.02 \%$, respectively. Fortunately, trans isomers of unsaturated fatty acids were detected in very low amounts $(0.02-0.12 \%)$ in the studied mushrooms (Table 2). A rapidly expanding literature documents the importance of trans fatty acids (TFAs) in human health due to the increased risk of cardiovascular disease where they are negatively correlated with plasma HDL-cholesterol concentration and positively correlated with plasma LDL-cholesterol level [16]. It is also important to point out that, in contrast to other fungi $[17,18]$, no other fatty acids with an odd number of carbon atoms have been detected in considerable amounts.

In previously studies, sixteen species of wild edible mushrooms found in Poland contained 66-82\% linoleic acid and $10-20 \%$ palmitic acid, whereas lauric, myristic, stearic, arachidic, oleic, and palmitic acids were in smaller fractions [19]. Linoleic and palmitic acids were the predominant fatty acids of both glycolipids and phospholipids in Pleurotus florida [20]. Saturated and monounsaturated fatty acids were 20.2 and $63.9 \%$ in P. ostreatus, respectively [6]. Linoleic and palmitic acids were 63.7 and $18.6 \%$ in F. velutipes, respectively [2].

In general, approximately $70 \%$ of fatty acids were the same in all species included in this study. In addition, results indicated that mushrooms were rich in polyunsaturated fatty acids, especially $18: 2$. Also, mushrooms are rich in essential fatty acids and therefore should be contained in the diet.

\section{Conclusion}

Edible mushrooms can be regarded as healthy foods-low in fat. Low calorie and low fat diets are recommended for people with high blood cholesterol. Therefore mushrooms are perfect, because of their low calories, low fat composition, and high essential fatty acid levels [6]. Most of the studies on mushroom fatty acids are limited to certain mushroom species. However, the present results indicate that economically important wild edible mushrooms contain significant amounts of valuable fatty acids. Therefore, studies should 
be performed on fatty acid contents of other economically important and edible mushrooms.

\section{References}

[1] L. Barros, P. Baptista, D. M. Correia, S. Casal, B. Oliveira, and I. C. F. R. Ferreira, "Fatty acid and sugar compositions, and nutritional value of five wild edible mushrooms from Northeast Portugal," Food Chemistry, vol. 105, no. 1, pp. 140-145, 2007.

[2] K. J. Lee, I. J. Yun, K. H. Kim et al., "Amino acid and fatty acid compositions of Agrocybe chaxingu, an edible mushroom," Journal of Food Composition and Analysis, vol. 24, no. 2, pp. 175$178,2011$.

[3] P. Bobek, L. Ozdín, and Š. Galbavý, "Dose- and time-dependent hypocholesterolemic effect of oyster mushroom (Pleurotus ostreatus) in rats," Nutrition, vol. 14, no. 3, pp. 282-286, 1998.

[4] J. S. Hong, Y. H. Kim, K. R. Lee, M. K. Kim, C. I. Cho, and K. K. H. Part, "Composition of organic abd fatty acid in Pleurotus ostreatus, Lentinus edodes and Agaricus bisporus," Korean Journal of Food Science and Technology, vol. 20, pp. 100-105, 1988.

[5] P. Bobek, E. Ginter, M. Jurcovicova, and L. Kuniak, "Cholesterol-lowering effects of the mushroom Pleurotus ostreatus in hereditary hypercholesterolemic rats," Annals of Nutrition and Metabolism, vol. 35, no. 4, pp. 191-195, 1991.

[6] N. Yilmaz, M. Solmaz, I. Türkekul, and M. Elmastaş, "Fatty acid composition in some wild edible mushrooms growing in the middle Black Sea region of Turkey," Food Chemistry, vol. 99, no. 1, pp. 168-174, 2006.

[7] D. Wang, A. Sakoda, and M. Suzuki, "Biological efficiency and nutritional value of Pleurotus ostreatus cultivated on spent beer grain," Bioresource Technology, vol. 78, no. 3, pp. 293-300, 2001.

[8] C. Li, Z. Li, M. Fan et al., "The composition of Hirsutella sinensis, anamorph of Cordyceps sinensis," Journal of Food Composition and Analysis, vol. 19, no. 8, pp. 800-805, 2006.

[9] S. Zacharia and A. Doshi, "Artificial indoor cultivation of Tricholoma crassa (Berk.) Sacc. an ectomycorrhizal mushroom using some local substrates," Journal of Mycology and Plant Pathology, vol. 34, pp. 125-126, 2004.

[10] ISO 5509, "Animal and vegetable fats and oils-preparation of methyl esters of fatty acids," 2000.

[11] F. Senatore, A. Dini, and A. Marino, "Chemical constituents of some Basidiomycetes," Journal of the Science of Food and Agriculture, vol. 45, pp. 337-345, 1988.

[12] R. S. Goodhart and M. E. Shils, Modern Nutrition in Health and Disease, Lea and Febinger, Philadelphia, Pa, USA, 6th edition, 1980.

[13] P. Kalač, "Chemical composition and nutritional value of European species of wild growing mushrooms: a review," Food Chemistry, vol. 113, no. 1, pp. 9-16, 2009.

[14] L. Ruess, M. M. Häggblom, E. J. García Zapata, and J. Dighton, "Fatty acids of fungi and nematodes-possible biomarkers in the soil food chain?" Soil Biology and Biochemistry, vol. 34, no. 6, pp. 745-756, 2002.

[15] J. A. Maga, "Mushroom flavor," Journal of Agricultural and Food Chemistry, vol. 29, no. 1, pp. 1-4, 1981.

[16] T. Minamide and J. B. W. Hammond, "The influence of the periodic fruiting (flushing) cycle on the biochemical development of Agaricus bisporus sporophores," New Phytologist, vol. 100, pp. 571-578, 1985.
[17] V. A. Díez and A. Alvarez, "Compositional and nutritional studies on two wild edible mushrooms from northwest Spain," Food Chemistry, vol. 75, no. 4, pp. 417-422, 2001.

[18] T. Longvah and Y. G. Deosthale, "Compositional and nutritional studies on edible wild mushroom from northeast India," Food Chemistry, vol. 63, no. 3, pp. 331-334, 1998.

[19] J. Szymczak, "Chemical composition of lipids of edible mushrooms. Part II. Fatty acids content in phospholipids," Bromatologia i Chemia Toksykologiczna, vol. 11, no. 3, pp. 335-343, 1978.

[20] V. J. Kwon and T. B. Uhm, "A studies on the lipid components in oyster mushroom (Pleurotus florida)," Journal of the Korean Society of Food Science and Nutrition, vol. 13, no. 2, pp. 175-180, 1984. 


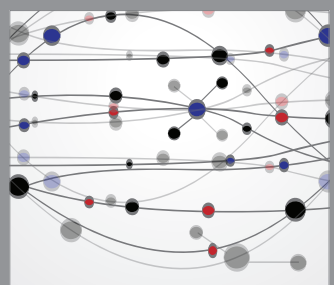

The Scientific World Journal
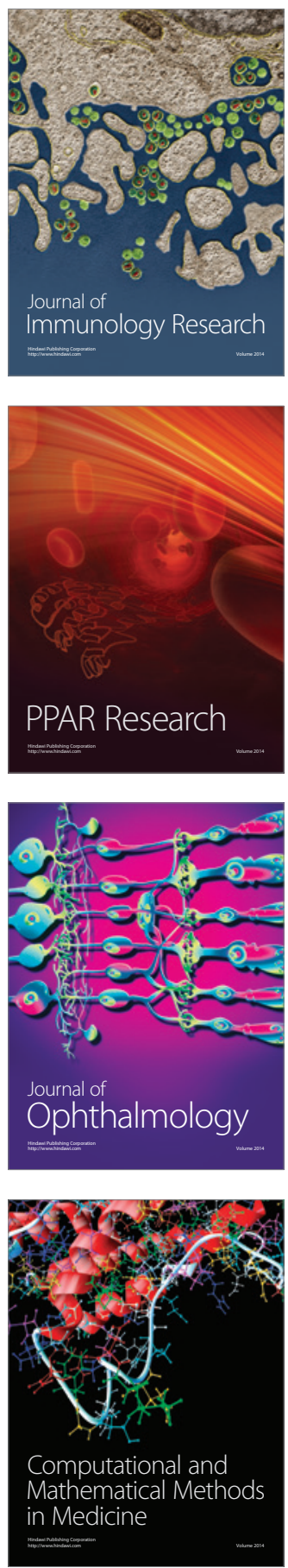

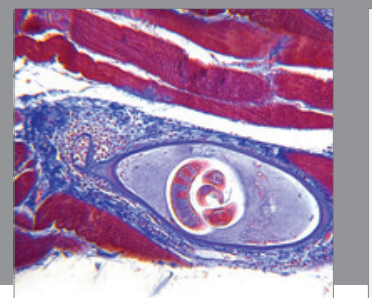

Gastroenterology

Research and Practice
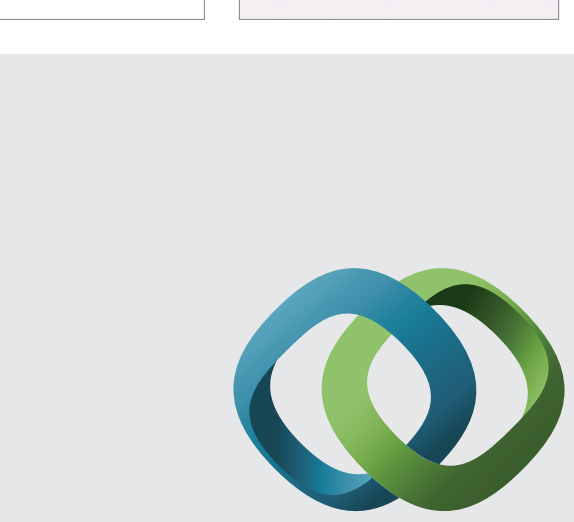

\section{Hindawi}

Submit your manuscripts at

http://www.hindawi.com
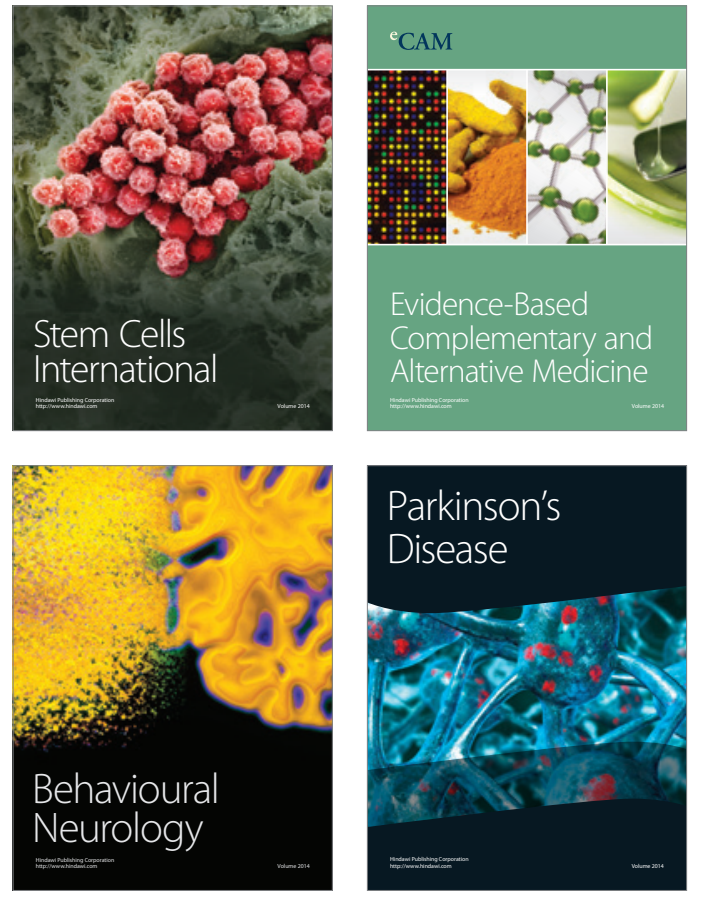
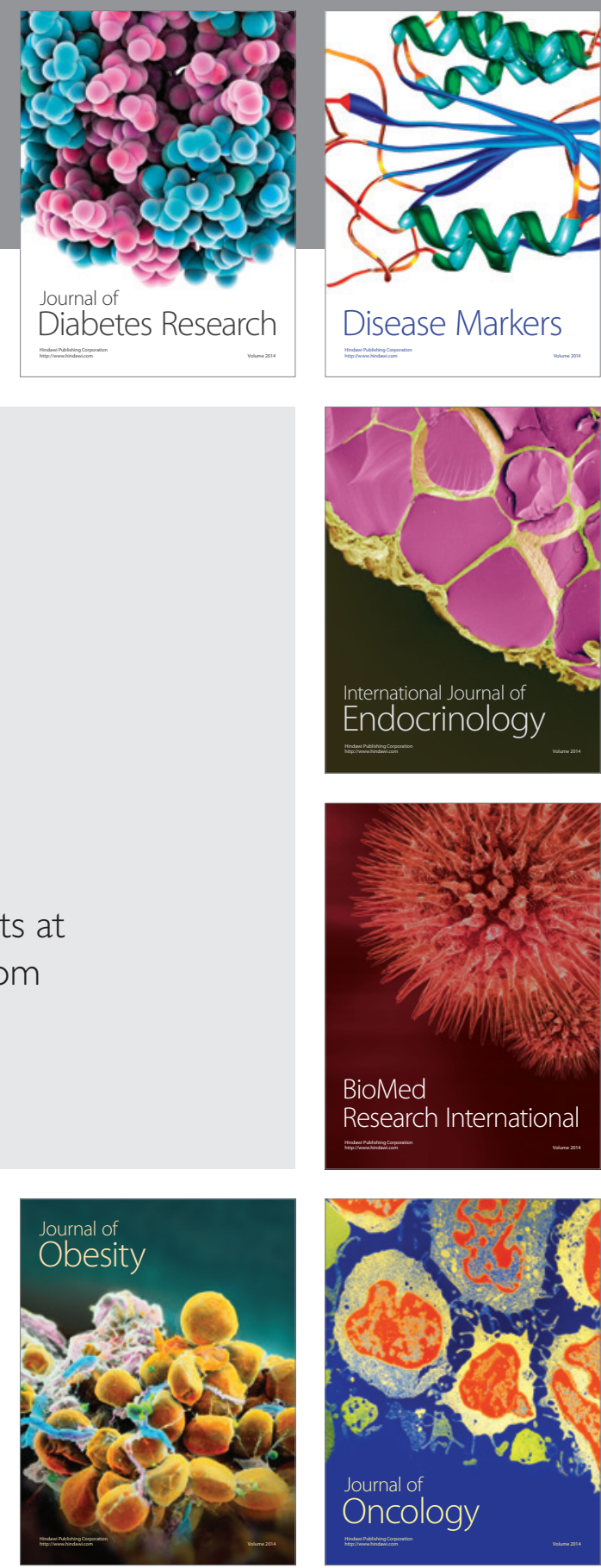

Disease Markers
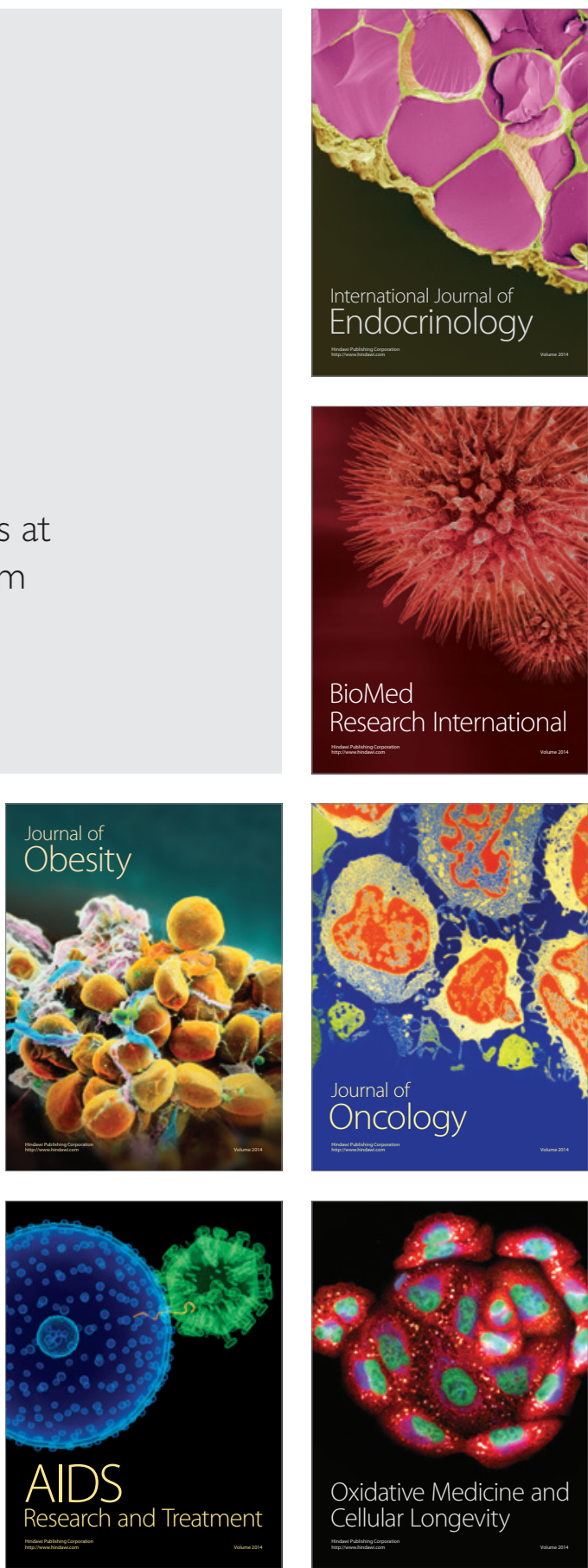